\title{
Economic Burden of Cancer Treatment in a Region in South India: A Cross Sectional Analytical Study
}

\author{
Pradeep Kumar Maurya ${ }^{1}$, Sharan Murali', Venkatachalam Jayaseelan ${ }^{1 *}$, \\ Mahalakshmy Thulasingam ${ }^{1}$, Jagadeshan Pandjatcharam²
}

\begin{abstract}
Introduction: The rising cost of cancer diagnosis and treatment has imposed a huge financial burden on the affected households. Understanding the nature of this burden will help us to formulate plans to avoid financial distress among the same. Objective: The study aims to estimate the Out of Pocket Expenditure (OOPE) for the management of selected solid cancers among the Out-Patient Department (OPD) of Regional Cancer Centre in South India and to determine the proportion of families experiencing Catastrophic Health Expenditure (CHE) due to the same. Methods: A hospital based cross sectional analytical study was undertaken in the authors' institute in South India. 474 solid cancer patients were interviewed in OPD of Radiation Oncology by a trained data collector. Sociodemographic variables, costs incurred under various headings and expenditure details of participants were obtained. Direct Medical and Direct Non-Medical costs were calculated, and its total was used as the OOPE. Costs were presented as mean with its standard error. Incidence of CHE was calculated using the $40 \%$ threshold on the Capacity to pay and was expressed as proportions with $95 \%$ confidence interval. Appropriate statistical tests were used to look for statistically significant differences in the study groups. Results: The average OOP expenditure incurred by a cancer patient was INR 35,817 (USD 523.6) for male and INR 20,496 (USD 299.6) for female. Males had a significantly higher OOPE than females. The prevalence of catastrophic health expenditure (CHE) was $61.6 \%$ at the $40 \%$ CTP threshold. Patients who used insurance schemes had higher prevalence of CHE than those who did not use insurance schemes $(65.5 \% \mathrm{vs} 60.7 \%$, $\mathrm{p}$ value 0.351). Conclusion: Cancer care provided through public institutions had a low direct medical cost, but the indirect cost seemed to be extremely high. Public based financial assistance is the need of the hour to help the cancer affected families.
\end{abstract}

Keywords: Cancer burden- out of pocket expenditure- catastrophic health expenditure- economic burden

Asian Pac J Cancer Prev, 22 (12), 3755- 3762

\section{Introduction}

Among the growing burden of Non-Communicable Diseases (NCDs), cancer holds a major position by contributing to one among six deaths in the world. Cancer becomes the second leading cause of death in the year 2018 and contributes to $70 \%$ of the death in the Low- and Middle-Income Countries (LMIC). This huge burden of cancer could be fought through early detection and appropriate treatment.(WHO | "Cancer", n.d.) This is impeded by the high cost of diagnostics and treatment for cancer. The total annual economic cost of cancer in 2010, as estimated in the World Cancer Report 2014, was approximately USD 1.16 trillion. (BW and CP, n.d.)

As far as India is concerned, nearly 700 thousands deaths are attributed to cancer every year (Mallath et al., 2014; P and B, n.d.) With only $25 \%$ of the Indian population covered by any sort of health insurance, the cost associated with the diagnosis and treatment of this rising tide of cancer in India is huge (Reddy et al., n.d.). It's a known fact that the public expenditure on health in India is as low as $1.02 \%$ of Gross Domestic Product (GDP) and $61 \%$ of the total health expenditure is contributed by the people from their own pocket, rightly termed as Out of Pocket Expenditure (OOPE) (CBHI, 2019). Around 3.5\% of the Indian population gets pushed below poverty line each year due to increased OOPE (Berman et al., 2010; Garg and Karan, 2009; van Doorslaer et al., 2006)The odds of impoverishment as well as catastrophe due to treatment of cancer were found to be $133 \%$ and $180 \%$ more than the odds due to any other communicable disease in India. (Engelgau et al., 2012)

Diagnostics and treatment contribute to the direct medical cost of any illness. The direct non-medical costs, the indirect and intangible costs associated with cancer is also huge. Nearly $70 \%$ of the total deaths due to cancer

${ }^{1}$ Department of Preventive and Social Medicine, JIPMER, India. ${ }^{2}$ Department of Radiation Oncology, JIPMER, India. *For Correspondence: drvenkatpgi@gmail.com 
occur in the people between the age group of 30-69 years. ("Cancer mortality in India: a nationally representative survey - The Lancet," n.d.) Thus, we understand that, cancer not only consumes a major portion of the family budget, but also affects the socio-economic wellbeing of the family. This inability to pay for cancer diagnosis and treatment greatly hinders the cancer fighting efforts of the nation (Rajpal et al., 2018). While the world is ambitiously moving towards the goal of universal health coverage (UHC), a thorough understanding of the financial burden of major cancers in the Indian population, becomes the need of the hour (Kumar and Roy, 2016).

Multiple attempts were made in the past to quantify the economic burden of cancers in the Indian context. Majority of them are a decade old and fail to bring out the OOPE associated with seeking medical care for cancer (al et al., 2011; Engelgau et al., 2012; Mondal et al., n.d.; "The Economic Burden of Cancers on Indian Households," n.d.) Understanding the expenditure pattern and OOPE by the cancer patients will help the scientific world to grab the attention of the policy makers to invest more in cancer management. This article aims to approach this problem among the cancer patients attending a tertiary care centre in the southern part of India.

Among the various sites of cancer, Head and Neck Cancers (HNCs) were found to be an emerging public health problem contributing to a total of $30 \%$ of all cancer cases in males and 11 to $16 \%$ of all cancer cases in females (Kulkarni, 2013). Southeast Asian region, majority from India, contribute to $57.5 \%$ of the global $\mathrm{HNC}$ cases. Attempts are being made on national level to quantify the rising burden of HNCs (Chauhan et al., 2019; Kulkarni, 2013. Breast Cancer and Cervical Cancer form the major types of cancer faces by women, with a prevalence of $25.9 \%$ and $10.8 \%$ respectively.("ncdir faCT SHEET," n.d.) This study was thus designed to capture the OOPE and the proportion of households' experiencing catastrophic health expenditure among the solid cancer (Head and Neck, Breast and Cervical) patients taking treatment and being followed up at the regional cancer centre attached to the authors' institute. An attempt was also made to capture the proportion of patients utilizing any available social insurance schemes.

\section{Materials and Methods}

\section{Study design and setting}

A hospital-based cross-sectional analytical study was conducted in the Regional Cancer Centre under the Department of Radiation Oncology at authors' institute in South India. The centre provides service to around 3,000 new cancer patients and around 40,000 patients on follow-up every year. Majority of these patients hail from Tamil Nadu and Puducherry state and belong to the low- and middle-income groups. All the diagnostics and treatment modalities are free of cost to the patients with a monthly family income of Rs 2000/- or less.

Patients are received at the Medical Registration Desk in the dedicated RCC building inside the campus. After collecting necessary details, patients are directed towards the consultation area where they meet the radiation oncologist. Necessary investigations will be advised, and treatment plans will be made accordingly. The patients would also get registered into the hospital-based cancer registry and can avail counselling services as required for maintaining adequate follow up. Patients who get diagnosed in the authors ' institute and outside are treated with equal vigour in the RCC.

\section{Sample size and Sampling technique}

Considering the mean OOPE (SD) for treatment of solid cancers as INR 67,480 (8152), sample size was calculated with $95 \%$ confidence interval and $8 \%$ relative precision as 600.25 (Chauhan et al., (2019). We decided to include 600 individuals satisfying the eligible criteria into our study. Sample size was calculated using the formula $\mathrm{Z}^{2}(\mathrm{SD})^{2} / \mathrm{d}^{2}$ were $\mathrm{Z}$ refers to the $\mathrm{Z}$ score for the $95 \%$ confidence interval, and SD for standard deviation from existing literature and $\mathrm{d}$ for absolute precision. All eligible patients were recruited into the study as soon as they finish their consultation with the doctor by a consecutive sampling technique during the two-month data collection period from September to October 2019.

\section{Study Procedure}

After obtaining a written informed consent from the participants, data collection was done using a pretested interview schedule. Socio-demographic details were obtained from the patient's case sheet. Details of the money spent under various headings, startingwith diagnostics, treatment, transportation to the hospital, food expenses during hospital visits, accommodation expenses etc during the last one year were carefully noted down. Since participants were finding it difficult to comprehend the loss of wage due to hospital visits and other indirect costs associated with the present illness clearly, these were not collected.

Data was also collected regarding the expenditure pattern of the family. Self-reported registration and availing benefits of any central or state government insurance scheme for the current illness were noted down as Health Insurance Scheme utilization. Data was collected by the principal investigator himself after obtaining adequate training and was entered directly into EpiCollect, a mobile based application for data collection. ("Epicollect5 - Mobile and Web Application for free and easy data collection.," n.d.).

\section{Cost Calculations - Patient Perspective}

All expenses incurred from the patient pocket for the diagnosis, treatment and for other non-medical domains for the present cancer related illness over the past one year were considered as Out of Pocket Expenditure (OOPE) in this study. OOPE was grouped under two headings - Direct Medical and Direct Non-Medical. Cost of consultation, drug charges, laboratory charges, ultrasound charges, surgery, blood transfusion and medical materials expenses were included as direct medical cost. Direct non-medical costs included transportation charges, food expenses and accommodation expenses, if any, for both the patient and the caretaker ("Estimating the direct and indirect costs of lung cancer: a prospective analysis in a Greek University 
Pulmonary Department. - PubMed - NCBI," n.d.). Each of these costs were carefully obtained and the total OOPE was calculated as the sum of both these costs. All costswere reported in Indian National Rupees (INR).For international comparison, expenses were converted into USD using a conversion rate of 1 INR to 68.4 USD for the year 2018, as reported by the World Bank and reported in parenthesis.

Total family expenditure pattern was obtained from the patient or the caregiver. This was used to calculate Capacity to Pay (CTP). CTP was defined as the total non-food expense of the family (Total Household Expenses (THE) - Food Expenses (FE)) per month. This monthly CTP was multiplied by 12 to get the annual CTP. Catastrophic Health Expenditure (CHE) was deemed to be present if the health expenditure of the family for the present cancer related illness (total OOPE) was more than or equal to $40 \%$ of the annual CTP. ("WHO | Out-of-pocket payments, user fees and catastrophic expenditure," n.d.).

\section{Statistical Analysis}

Age was treated as a continuous non-normally distributed variable and was summarised as median with IQR. Age was later converted to a categorical form and was presented as frequency with proportion along with other variables like gender, religion, place of residence, state of origin, educational status, occupation, marital status, type of family, type of ration card, site of cancer and stage of cancer. The Socioeconomic Status was calculated using the per capita income obtained from the data based on the Modified BG Prasad Classification 2019 update which classified social class into five levels as Upper, Upper Middle, Middle, Lower Middle and Lower based on per capita income as INR 7008 (USD 95.40) and above, INR 3504 (USD 47.70) to 7007 (USD 95.38), INR 2102 (USD 28.61) to INR 3503 (USD 47.68), INR 1051 (USD 14.31) to INR 2101 (USD 28.60), INR 1050 (USD 14.29) and below (Pandey et al., 2019).

Direct medical and Direct non-medical costs for each of the above discussed independent variable categories were summarised as mean with standard error (SE). Overall, total OOPE was also calculated and presented as mean with SE. Presence of Catastrophic health expenditure in the study population was calculated and presented as frequency (proportion) with 95\% confidence interval. The same was calculated for the various sites of cancer and for health insurance categories. Mann Whitney U Test and Kruskal Wallis test was used to look for statistically significant differences on the total OOPE between the study groups. Chi square test was used to look for any significant association between the groups for the presence or absence of CHE. A p value of $<0.05$ will be considered significant in all the test. Data was analysed using STATA software version 12.

\section{Results}

\section{Participants Characteristics}

Eligibility was assessed among the 600 patients who were receiving care from the OPD of the RCC.
Sixty were found to be ineligible, fifty were not able to comprehend instructions and another sixteen did not give consent. Therefore, a total of 474 participants were finally interviewed. Median (IQR) age of the participants was 55 (22-85) years. Nearly $62 \%$ of the participants were aged more than 50 years. Seventy-four percent of the participants were females and $71 \%$ hailed from Tamil Nadu. 54\% of the participants were from an urban background. Almost half $(48.3 \%)$ of the participants received no formal education and around $47 \%$ belonged to the lower socioeconomic class. Among the 474 participants, the site of cancer was almost equally distributed. Stage of cancer data was missing for nearly 108 (38.8\%) participants. 245 participants $(51.7 \%)$ belonged to stage two of the disease. Only $24.6 \%$ of the study participants reported utilization of any health insurance scheme. Table 1 gives the elaborate socio-demographic picture of the study population.

\section{Out of Pocket Expenditure}

The average OOP expenditure (SE) for a patient receiving care for either of the solid cancer in this RCC in South India was found to be INR 1551.2 (USD 22.7) with a standard error of INR 414.8 (USD 6.1) as Direct Medical and INR 22,823.4 (USD: 333.7) with SE INR 2927.4(USD 42.8) as Direct Non-Medical. Direct medical cost was highest in the 51-60 years age group (INR 2246, USD 32.8) whereas direct non-medical cost spent was highest in the 61+ age group (INR 37543, USD 548.9). The average OOP expenditure incurred by a male cancer patient was INR 35,817 (USD 523.6) and by a female patient was INR 20,496 (USD 299.6). Male patients were spending more as direct non-medical when compared to that of females (INR 34,545.1 vs INR 18,849.9, USD 505 vs USD 275.6). The difference in OOPE between males and females were found to be statistically significant ( $p$ value $<0.001$ ). Table 2 gives the section wise direct medical and direct non-medical expenses experienced by the participants.

The OOP expenditure for class IV of the Modified BG Prasad classification was higher than that of the other classes. This might be due to the high direct non-medical cost spent by class IV (INR 35497, USD 519) patients. On comparing the OOPE based on residence, we see that urban patients were spending more as compared to their rural counterparts. (INR 25,785 (USD 377) vs INR 22,744 (USD 332.5), p value 0.046). Patients employed in the government sector spent highest direct medical cost of INR 2181 (USD 31.9) and pensioners spent highest indirect medical cost of INR 40,532 (USD 592.6). The difference in the total OOPE among the various occupational groups were found to be statistically significant. Patients with no ration card spent highest direct (INR 2143, USD 31.3) and indirect medical cost (INR 35,357 , USD 516.9) when compared to those with above and below poverty line ration cards ( $\mathrm{p}$ value $<0.001$ ).

Average money spent by cervical cancer patients on direct medical cost was INR 2518 (USD 36.8) as compared to INR 1334 (USD 19.5) spent by Head and Neck cancer patients. Indirect medical cost spent was more in Head and Neck cancer patients (INR 30,294, USD 442.9) as compared to Breast cancer patients (INR 24,547, USD 
Table 1. Sociodemographic and Disease characteristics of the Solid cancer patients availing treatment from the Out-Patient Department of Regional Cancer Centre in South India $(\mathrm{N}=474)$

\begin{tabular}{|c|c|c|c|}
\hline & Variable & Frequency & Percentage \\
\hline \multirow[t]{6}{*}{1} & Age & & \\
\hline & Below 30 & 8 & 1.7 \\
\hline & $31-40$ years & 42 & 8.9 \\
\hline & $41-50$ years & 131 & 27.6 \\
\hline & $51-60$ years & 171 & 36.1 \\
\hline & 61 and above & 122 & 25.7 \\
\hline \multirow[t]{3}{*}{2} & Gender & & \\
\hline & Male & 120 & 25.3 \\
\hline & Female & 354 & 74.7 \\
\hline \multirow[t]{4}{*}{3} & Religion & & \\
\hline & Hindu & 433 & 91.3 \\
\hline & Muslim & 25 & 5.3 \\
\hline & Christian & 16 & 3.4 \\
\hline \multirow[t]{3}{*}{3} & Residence & & \\
\hline & Urban & 254 & 53.6 \\
\hline & Rural & 220 & 46.4 \\
\hline \multirow[t]{5}{*}{4} & State & & \\
\hline & Pondicherry & 105 & 22.1 \\
\hline & Tamilnadu & 340 & 71.7 \\
\hline & West Bengal & 27 & 5.7 \\
\hline & Jharkhand & 2 & 0.5 \\
\hline \multirow[t]{5}{*}{5} & Education & & \\
\hline & No formal education & 229 & 48.3 \\
\hline & Primary & 143 & 30.2 \\
\hline & Secondary & 70 & 14.8 \\
\hline & Higher Secondary and above & 32 & 6.7 \\
\hline \multirow[t]{6}{*}{6} & Occupation & & \\
\hline & Unemployed & 315 & 66.5 \\
\hline & Daily Wage & 139 & 29.3 \\
\hline & Private Job & 6 & 1.3 \\
\hline & Government & 10 & 2.1 \\
\hline & Pensioner & 4 & 0.8 \\
\hline \multirow[t]{4}{*}{6} & Marital Status & & \\
\hline & Married & 420 & 88.6 \\
\hline & Widow & 49 & 10.3 \\
\hline & Divorce & 5 & 1.1 \\
\hline \multirow[t]{3}{*}{7} & Type of Family & & \\
\hline & Nuclear & 306 & 64.6 \\
\hline & Joint & 168 & 35.4 \\
\hline \multirow[t]{4}{*}{8} & Type of Ration Card & & \\
\hline & Above poverty Line & 315 & 66.5 \\
\hline & Below Poverty Line & 64 & 13.5 \\
\hline & No ration card & 95 & 20.0 \\
\hline \multirow[t]{6}{*}{9} & Socio-Economic Status\# & & \\
\hline & Class I (INR 7008 and above) & 10 & 2.1 \\
\hline & Class II (INR 3504-7007) & 27 & 5.7 \\
\hline & Class III (INR 2102-3503) & 73 & 15.5 \\
\hline & Class IV (INR 1051-2101) & 138 & 29.2 \\
\hline & Class V (Below INR 1050) & 224 & 47.5 \\
\hline
\end{tabular}

Table 1. Continued

\begin{tabular}{llcc}
\hline & Variable & Frequency & Percentage \\
\hline $10 \quad$ Site of Cancer & & \\
& Breast Cancer & 165 & 34.8 \\
& Head \& Neck Cancer & 157 & 33.1 \\
& Cervical Cancer & 152 & 32.1 \\
& Stage of Cancer & & \\
& I & 17 & 3.5 \\
& II & 245 & 51.7 \\
& III & 104 & 21.9 \\
& Missing & 108 & \\
Health insurance utilisation & & \\
& Ever utilised & 116 & 24.6 \\
& Never utilised & 356 & 75.4 \\
\end{tabular}

\# Pandey, V.K., Aggarwal, P., Kakkar, R., 2019. Modified BG Prasad Socio-economic Classification, Update - 2019 31, 3.

358.9) and cervical cancer patients (INR 13,235, USD 193.5). The difference in OOPE between the various sites of cancer was found to be statistically significant ( $\mathrm{p}$ value $<0.004$ ). Highest direct medical cost was spent in stage 1 cancer patients (INR 1903, USD 27.8) and highest indirect medical cost was spent in stage 3 cancer patients (INR 22,932, USD 335.3). Patients who have never utilized health insurance were found to spend more in than those who have ever utilised a scheme (INR 26277.6 vs INR 23853.1, (USD 384.2 vs USD 348.7), p value $<0.001$ ).

\section{Catastrophic Health Expenditure and Health Insurance Utilisation}

The data on household expenditure pattern and the OOPE was analysed to explore the proportion of households suffering catastrophic health expenditure from the ongoing cancer management. It was observed that $61.6 \%$ (95\% CI: $54.7-69.1 \%)$ of the individuals were found to have catastrophic health expenditure. When data was analysed based on the site of cancer, it was observed that $61 \%$ of all the sites of cancer studied were found to have catastrophic health expenditure. Chi square test reported no significant difference in the number of individuals with CHE based on the site of cancer i.e. breast, cervical, head and neck. (Chi square value $=0.0165$, $\mathrm{p}$ value $=0.992$ )

Upon cross tabulating the health insurance utilization and CHE presence, it was observed that among the patients who has ever utilised any health insurance scheme, 65.5\% (95\% CI: 51.6 - 82\%) has suffered CHE, while among those who has never utilised any health insurance scheme, 60.7\% (95\% CI: 52.8 - 69.3\%) suffered CHE. This difference was found to be statistically insignificant $($ Chi square $=0.8698, \mathrm{p}$ value $=0.351)$.

\section{Discussion}

Increasing prevalence of Cancer with added difficulty levels of inadequate access to health facilities, long waiting lists for diagnostic tests and costly treatment modalities in a developing nation like India should get more research and policy attention. Although nationwide 
DOI:10.31557/APJCP.2021.22.12.3755

Economic Burden of Solid Cancers in South India

Table 2. Direct Medical and Direct Non-Medical Costs Incurred by the Solid Cancer Patients Availing Treatment from the Out-Patient Department of Regional Cancer Centre in South India ( $N=474)$

\begin{tabular}{|c|c|c|c|c|c|}
\hline Sl No & Variable & $\begin{array}{c}\text { Frequency (Proportion) } \\
\mathrm{n}(\%)\end{array}$ & $\begin{array}{c}\text { Direct } \\
\text { Mean (SE) in INR }\end{array}$ & $\begin{array}{c}\text { Direct } \\
\text { Mean (SE) in INR }\end{array}$ & $\mathrm{p}$ value\# \\
\hline 1 & Total & $474(100)$ & $1551.2(414.8)$ & $22823.4(2927.4)$ & \\
\hline 2 & Age Category & & & & \\
\hline $\mathrm{a}$ & Below 30 & $8(1.7)$ & $1825.9(936.5)$ & $5800.8(2647.3)$ & 0.663 \\
\hline $\mathrm{b}$ & $31-40$ years & $42(8.9)$ & $1366.7(342.6)$ & $10738(1424.7)$ & \\
\hline $\mathrm{c}$ & $41-50$ years & $131(27.6)$ & $1380.6(350.2)$ & $17030.4(2340)$ & \\
\hline $\mathrm{d}$ & 51-60 years & $171(36.1)$ & $2246.9(1107.5)$ & $20524.0(2414.5)$ & \\
\hline e & 61 and above & $122(25.7)$ & $804.6(168)$ & $37543.4(10458)$ & \\
\hline 3 & Gender & & & & \\
\hline $\mathrm{a}$ & Male & $120(25.3)$ & $1271.7(399.9)$ & $34545.1(4559.1)$ & $<0.001$ \\
\hline $\mathrm{b}$ & Female & $354(74.7)$ & $1645.9(538.8)$ & $18849.9(3581)$ & \\
\hline 4 & Residence & & & & \\
\hline $\mathrm{a}$ & Urban & $254(53.6)$ & $2195.3(765.5)$ & $23591(5169)$ & 0.046 \\
\hline $\mathrm{b}$ & Rural & $220(46.4)$ & $807.5(119.5)$ & $21937.2(2057.6)$ & \\
\hline 5 & State & & & & \\
\hline $\mathrm{a}$ & Pondicherry & $105(22.1)$ & $981.2(159.5)$ & $11648.4(3890.3)$ & $<0.001$ \\
\hline $\mathrm{b}$ & Tamilnadu & $340(71.7)$ & $1729.6(574.9)$ & $26980.1(3854)$ & \\
\hline $\mathrm{c}$ & West Bengal & $27(5.7)$ & $1548.3(460.3)$ & $15629.4(5673.6)$ & \\
\hline $\mathrm{d}$ & Jharkhand & $2(0.5)$ & $1186.9(38.0)$ & 0 & \\
\hline 6 & Socio-Economic Status & & & & \\
\hline $\mathrm{a}$ & Upper & $10(2.1)$ & $861.6(517.5)$ & $20715.1(9816.2)$ & 0.151 \\
\hline $\mathrm{b}$ & Upper middle & $27(5.7)$ & $962.3(375.1)$ & $25019.1(4949.1)$ & \\
\hline $\mathrm{c}$ & Middle & $73(15.5)$ & $3781(2556.0)$ & 20501.9 (3836.4) & \\
\hline $\mathrm{d}$ & Lower middle & $138(29.2)$ & $1081.1(205.0)$ & 35497 (9407.8) & \\
\hline e & Lower & $224(47.5)$ & $1227.4(240.1)$ & $15720.6(1486.5)$ & \\
\hline 7 & Occupation & & & & \\
\hline $\mathrm{a}$ & Unemployed & $315(66.5)$ & $1458(602.2)$ & $24077.4(4127.3)$ & 0.04 \\
\hline $\mathrm{b}$ & Daily Wage & $139(29.3)$ & $1717.2(366.4)$ & $21324.6(3378.4)$ & \\
\hline $\mathrm{c}$ & Private Job & $6(1.3)$ & $1529.8(631.0)$ & $609.4(199.2)$ & \\
\hline $\mathrm{d}$ & Government & $10(2.1)$ & 2181.5 (934.9) & $10400.6(2869.3)$ & \\
\hline e & Pensioner & $4(0.8)$ & $1572.1(1262.6)$ & 40532.1(29161.8) & \\
\hline 8 & Type of Family & & & & \\
\hline $\mathrm{a}$ & Nuclear & $306(64.6)$ & $1521(630.5)$ & 20452.4 (2013.6) & 0.545 \\
\hline $\mathrm{b}$ & Joint & $168(35.4)$ & $1606.1(228.7)$ & $27142.0(7404.1)$ & \\
\hline 9 & Type of Ration Card & & & & \\
\hline a & Above poverty Line & $315(66.5)$ & $1468.6(601.8)$ & $20927.4(1743.4)$ & $<0.001$ \\
\hline $\mathrm{b}$ & Below Poverty Line & $64(13.5)$ & $1079(186.5)$ & $13549.6(6015.1)$ & \\
\hline $\mathrm{c}$ & No ration card & $95(20.0)$ & $2143.1(534.7)$ & $35357.8(12756.9)$ & \\
\hline 10 & Site of Cancer & & & & \\
\hline $\mathrm{a}$ & Breast & $165(34.8)$ & $866.0(153.1)$ & $24547.6(7458.5)$ & 0.004 \\
\hline $\mathrm{b}$ & Cervical & $157(33.1)$ & $2518.9(1239)$ & $13235.2(1806.5)$ & \\
\hline $\mathrm{c}$ & Head \& Neck & $152(32.1)$ & $1334.3(317.9)$ & $30294.2(3602.6)$ & \\
\hline 11 & Stage of Cancer & & & & \\
\hline $\mathrm{a}$ & I & $17(3.5)$ & $1903.9(555.0)$ & $4264(1588.2)$ & 0.064 \\
\hline $\mathrm{b}$ & II & $245(51.7)$ & $1063.9(140.4)$ & 21673.4(3754.4) & \\
\hline $\mathrm{c}$ & III & $104(21.9)$ & $1496.7(483.5)$ & $22932.8(4145.5)$ & \\
\hline $\mathrm{d}$ & Missing & $108(22.8)$ & $2653.5(1730.6)$ & $28248.2(8749.0)$ & \\
\hline 12 & Health Insurance Utilization & & & & \\
\hline $\mathrm{a}$ & Ever & $116(24.6)$ & $643.4(141)$ & $25634.2(3013)$ & $<0.001$ \\
\hline $\mathrm{b}$ & Never & $356(75.4)$ & $1853.4(549.6)$ & $21999.7(3772.4)$ & \\
\hline
\end{tabular}

\# Mann Whitney U Test and Kruskal Wallis Test were used for two groups and more than 2 groups respectively. P values $<0.05$ were considered significant. 
Table 3. Proportion of Study Population with Catastrophic Health Expenditure (CHE) Present due to Cancer Treatment $(\mathrm{N}=474)$

\begin{tabular}{|c|c|c|c|c|}
\hline Sl No & Variable & CHE Present n (\%) & $95 \%$ Confidence Interval & $\mathrm{p}$ value\# \\
\hline 1 & Overall & $292(61.60)$ & $54.7-69.1$ & \\
\hline 2 & Site of Cancer & & & \\
\hline $\mathrm{a}$ & Breast & $101(61.21)$ & $53.3-68.6$ & 0.992 \\
\hline $\mathrm{b}$ & Cervical & $94(61.84)$ & $53.6-69.5$ & \\
\hline $\mathrm{c}$ & Head \& Neck & 97 (61.78) & $53.6-69.4$ & \\
\hline 3 & Health Insurance Utilisation & & & \\
\hline $\mathrm{a}$ & Ever utilised & $76(65.5)$ & $51.6-82.0$ & 0.351 \\
\hline $\mathrm{b}$ & Never Utilised & $216(60.7)$ & $52.8-69.3$ & \\
\hline
\end{tabular}

Foot Note: 1. Out of Pocket Expenditure more than $40 \%$ of the Capacity to Pay (Total Household Expenditure - Food Expenditure) was considered as Catastrophic Health Expenditure Positive -Reference: WHO | Out-of-pocket payments, user fees and catastrophic expenditure [WWW Document], n.d, WHO; 2. Chi Square test was performed to compare the numbers in the CHE present/absent with the variable groups. A p value $<0.05$ were considered significant.

representative sample surveys have proved the rising need for quality population-based screening systems and financial aid for cancer treatment, these do not get reflected in the policy documents and practice guidelines. Major findings of this present study were comparable with the available evidence from premiere cancer centres in other parts of India.

\section{Patient Characteristics}

With nearly $60 \%$ of the study population aged more than 50 years, the age distribution of the study participants of the present study goes hand in hand with a study conducted among HNC patients in North India(Chauhan et al., 2019). The same could be explained by the higher prevalence of cancer among the individuals aged 50+ in India(Rajpal et al., 2018). The present study had more males than females, even though cancer was more prevalent among the female gender. The present study had more individuals from the lowest class. The rich might be preferring to get their treatment from any of the seven private hospitals in the district, owing to less waiting time. The utilization rate of health insurance was at around 25\%, which is lesser than the same reported from North India (Chauhan et al., 2019).

\section{Out of Pocket Expenditure}

From the current study, we learn that the direct medical cost and the direct non-medical cost for cancer treatment in a public facility in south India was INR 1271 (USD 18.6) and INR 34,545 (USD 505), respectively. Addition of both i.e. total OOP Expenditure was INR 35,816 (USD 523.6), which was slightly lesser than the total OOPE reported for HNC from New Delhi in 2006 (INR 36,812, USD 538.2) (al et al., 2011). A similar study conducted in the radiation oncology department of PGI, Chandigarh in 2017 reported the OOPE of a HNC patient to be INR 37,845 (USD 553.3) (Chauhan et al., 2019). Thus we see that in the premiere institutions in India for quality medical care, the OOPE was almost similar with minor variations which could be attributed to the living cost in the three cities.

Present study concentrated on the expenses of OPD based care received by the cancer patients. A cross sectional analysis of the 71 st round of Morbidity and
Healthcare Survey organized by NSSO, Ministry of Statistic and Program Implementation across India, showed a total OOPE for hospitalization of cancer patients as INR 29,006 (USD 424.1). (Rajpal et al., 2018)Thus, we see that treatment for cancer both out-patient and inpatient are heavy priced and leads to financial distress.

Major part of the OOP Expenditure (96\%) was in the direct non-medical domain. This could be explained by the fact that, even though diagnostics and treatment is provided free of cost or at subsidised rates, the patients need to spend a lot more to reach the health facility and to stay and get treated. Insurance schemes available in the country cover up only the treatment cost and fail to take care of the direct non-medical costs. This is observed by the significantly lower direct medical cost among the individuals who use any type of health insurance and the higher direct non-medical cost in the same group when compared to that of the individuals who have never used insurance.

The older age group (51+) was spending more money when compared to the younger groups. This could again be attributed to the extra expense of travelling to the health facility. We observe that individuals from Tamil Nadu were spending more money to avail treatment from the RCC than the individuals from farther corners of the nation (West Bengal and Jharkhand). Individuals from Tamil Nadu prefer travelling by four-wheeler to reach the RCC, while individuals from the north prefer to travel by train to reach the city.

In contrast to the evidence that the richer households were spending more, in the present study we observed that the middle social economic class patients were spending more on the management of cancer (Chauhan et al., 2019; Rajpal et al., 2018). Individuals from urban settings were spending more than the ones from rural settings. This pattern is consistently seen in other parts of the country as well (Chauhan et al., 2019). HNC patients and stage 2 cancer patients were spending more than the other groups in their domain. This is in line with the similar study done at RCC, PGI, Chandigarh et al., (2019).

Present study also concentrated on Non-medical expenses and found that indirect cost incurred by the patients was very high. A similar retrospective observation 
study of 45 patients at CMC, Vellore, Tamilnadu observed the high expenses incurred as indirect cost.("View of Cost Analysis of Oral Cancer Treatment in a Tertiary Care Referral Center in India.pdf," n.d.).

\section{Catastrophic Health Expenditure}

The $40 \%$ cut off on the CTP was used to calculate the incidence of CHE in the present study. A $25 \%$ cut off could also be used, but that will include a bigger proportion than the current incidence of CHE. This $61.6 \%$ is a much higher incidence of $\mathrm{CHE}$ among the study population when compared to a similar study from North India (al et al., 2011; Chauhan et al., 2019). Although the total OOPE stays almost the same in the three studies, the higher proportion of $\mathrm{CHE}$ in the present study could be due to the lower overall income status of the families in the down south. This point needs to be further exploration. Whereas a study done in the Tata Memorial Centre, Mumbai has reported a $76.5 \%$ incidence of CHE with a $10 \%$ threshold on the total family expenditure (Basavaiah et al., 2018).

The consolidated evidence from NSSO data, tells us that more than $50 \%$ patients from low income households are reported to be spending more than 10 and $20 \%$ of per capita household expenditure whereas, about $26 \%$ of richer households are reported to be spending more than 10 and $20 \%$ of their annual income.(Rajpal et al., 2018) On comparing our data with that of 10 South East Asian Countries, we notice that our CHE rates were higher than the $48 \%$ reported by the ACTION study group van Doorslaer et al., (2006). A similar study from Nepal reported, $86.1 \%$ of families with cancer patients suffering from CHE. ("Frontiers $\mid$ Estimating the Direct Cost of Cancer in Nepal: A Cross-Sectional Study in a Tertiary Cancer Hospital | Public Health,” n.d.).

The incidence of the CHE was found to be almost the same in all sites of cancer, a similar study in a large public tertiary hospital in North India reported 62\% CHE incidence with $40 \%$ threshold among cervical cancer patients. Singh et al., (2020) our study was not able to appreciate a statistical difference between the insurance utilisation group and $\mathrm{CHE}$ incidence. High rates of $\mathrm{CHE}$ among the cancer patients in South India is an area of concern and needs to be thought about more objectively. As discussed before, the overall OOPE is contributed much by the direct non-medical costs. The insurance systems should be capable of supporting the patients in these difficult times with free or subsidized transport facilities. From a health system point of view, unnecessary travel can be avoided, and the patient can be tagged into their corresponding Primary Health Centre (PHC) for pain medications and health advice. Telemedicine is also an evolving field that could reduce the pain of travel and expenditure of both patient and the bystander. ("Telemedicine.pdf," n.d.) Further research should focus on quantifying the nature of follow up visits and how many of them could have been reduced.

\section{Strength and limitations}

The present study used a validated, pretested interview schedule in regional language for collecting information related to the economic burden caused by cancer treatment.
Last one-year data on the cost incurred was calculated, so that recollection was easy and quality of data could be ensured. The direct medical costs under various headings were collected, as this would reflect the expenditure pattern and would help in finding out the OOPE.

This was a cross-sectional attempt to quality the OOPE among selected cancer patients attending the OPD of an RCC in South India. And therefore, the results of the study may not be representative of all selected solid cancer and the treatment cost in the true population. NSSO reports that a higher proportion of cancer patients seek care from the private than from the public. And simultaneously the cancer treatment costs in private are higher compared to that of the public. Future research should follow a community-based approach to capture the health seeking behaviour and the economic burden of cancer.

We have used a patient perspective for capturing the cost involved in the treatment of cancer and OOPE. Indirect costs like wage loss, loss of employment because of being sick etc were not captured in the study, owing to its complexity in capturing. The picture of the economic burden of cancer, will get complete only if these were included. The study limited itself into collecting the OOPE pattern and did not probe into the coping strategies used by the families in overcoming this financial distress.

In conclusion, the total OOPE for solid cancer diagnosis and management was found to be INR 24,374.8 (USD 356.4) Although cancer diagnosis and management costs at the tertiary care institutions of the country are relatively less catastrophic on the family budget, the direct non-medical cost was found to be very high. A total of $61.6 \%$ of the study participants were experiencing $\mathrm{CHE}$ owing to their cancer treatment. This calls for strict policy action to invest on reducing the burden of direct non-medical expenses incurred by the patients. Community ambulance services, low cost rest houses and free or subsidised canteens for the patients and the caregivers would help tame this burden. More evidence needs to be generated to investigate the factors contributing to catastrophic health expenditure and to look for effectiveness of insurance schemes in reducing the financial burden on the cancer shaken families.

\section{Author Contribution Statement}

Pradeep Kumar Maurya: Conceived and designed the analysis, Collected the data, Contributed data or analysis tools, Performed the analysis, Wrote the paper, Other Contribution; Sharan Murali: Conceived and designed the analysis, Contributed data or analysis tools, Performed the analysis, Wrote the paper, Other Contribution; Venkatachalam Jayaseelan: Conceived and designed the analysis, Contributed data or analysis tools, Performed the analysis, Wrote the paper, Other Contribution; Mahalakshmy Thulasingam: Conceived and designed the analysis, Contributed data or analysis tools, Wrote the paper, Other Contribution; Pandjatcharam Jagadesan: Conceived and designed the analysis, Contributed data or analysis tools, Wrote the paper, Other Contribution.

Asian Pacific Journal of Cancer Prevention, Vol $22 \mathbf{3 7 6 1}$ 


\section{Acknowledgements}

The authors are thankful to the Patients, Faculty, Residents and Staff of the Department of Radiation Oncology for dedicating their valuable resources and efforts towards the data collection process of this study. We would also like to thank the faculty, residents, MPH students and office staff of the Department of Preventive andSocial Medicine for their wholehearted support.

\section{Funding Statement}

The authors have not received any funding for the conduct of this study. If it was approved by any scientific Body/ if it is part of an approved student thesis: This study is a part of an approved student (MPH Scholar) thesis.

How the ethical issue was handled (name the ethical committee that approved the research).Study is approved by JIPMER Institutional Ethics Committee.

\section{Availability of data}

Raw data was collected at Regional Cancer Centre JIPMER by structured questionnaire after consent from participants.

\section{Conflict of interest}

The Authors declare that there is no conflict of interest.

\section{References}

Aggarwal P, Pandey VK, Kakkar R (2019). Modified BG Prasad Socio-economic Classification, Update. Vol. 31. 2019. p. 3.

Ahuja R, Berman P, Bhandari L (2010). The Impoverishing Effect of Healthcare Payments in India: New Methodology and Findings. Economic and Political Weekly, 45, pp 65-71.

B L, P B. World Cancer Report 2008. Geneva: World Health Organisation; 2008.

B.K.M., Das S, Mukhopadhyay A, Sharma K, et al (2011). Estimating the economic burden of cancer at a tertiary public hospital: A Study at the All India Institute of Medical Sciences (Indian Statistical Institute, Planning Unit, New Delhi Discussion Paper. New Delhi, India: Indian Statistical Institute; 2011.

Badwe R, Mallath M, Rath G, et al (2014). The growing burden of cancer in India: epidemiology and social context. Lancet Oncol, 15, 205-12.

Basavaiah G, Rent PD, Rent EG, et al (2018). Financial impact of complex cancer surgery in India: A Study of Pancreatic Cancer. J Glob Oncol, 4, 1-9.

Central Bureau of Health Intelligence. New Delhi: Ministry of Health \& Family Welfare; 2019.

Centre for Genomic Pathogen Surveillance. Epicollect5 Mobile \& Web Application for free and easy data collection [Internet]. Available from: https://five.epicollect.net/.

Chacko R, Ramireddy J, Sundaram D (2017). Cost analysis of oral cancer treatment in a tertiary care referral center in India. Asian Pac J Cancer Biol, 2, 17-21.

Chauhan AS, Ghoshal S, Prinja S, et al (2020). Cost of treatment for cervical cancer in India. Asian Pac J Cancer Prev, 21, 2639-46.

Chauhan AS, Prinja S, Ghoshal S, Verma R (2019). Economic Burden of head and neck cancer treatment in North India. Asian Pac J Cancer Prev, 20, 403-9.

Dikshit R, Gajalakshmi V, Gupta PC, et al (2012). Cancer mortality in India: a nationally representative survey. Lancet,
379, 1807-16.

Doorslaer E van, O'Donnell O, Rannan-Eliya RP, et al (2006). Effect of payments for health care on poverty estimates in 11 countries in Asia: an analysis of household survey data. Lancet, 368, 1357-64.

Engelgau M, Fan VY, Karan A, Mahal A (2013). The economic burden of cancers on Indian households. PLoS One, 8, e71853.

Engelgau MM, Karan A, Mahal A (2012). The Economic impact of Non-communicable Diseases on households in India. Global Health, 8, 9.

Garg C, Karan A (2009). Reducing out-of-pocket expenditures to reduce poverty: a disaggregated analysis at rural-urban and state level in India. Health Policy Plan, 24, 116-28.

Governors B. Telemedicine Practice Guidelines. New Delhi: Medical Council of India \&NitiAyog; 2020.

Joe W, Kumar A, Rajpal S (2018). Economic burden of cancer in India: Evidence from cross-sectional nationally representative household survey, 2014. PLoS One, 13, 0193320.

Kanjilal B, Lucas H, Mondal S, Peters D (2014). Catastrophic out-of-pocket payment for healthcare and implications for household coping strategies: evidence from West Bengal, India. Economics Bull, 34, 1303-16.

Khatiwoda S, Dhungana R, Sapkota V, Singh S. Frontiers | Estimating the Direct Cost of Cancer in Nepal: A CrossSectional Study in a Tertiary Cancer Hospital | Public Health.

Kulkarni M (2013). Head and neck cancer burden in India. Int $J$ Head Neck Surg, 4, 29-35.

Kumar R, Roy P (2016). India in search of right Universal Health Coverage (UHC) model: The risks of implementing UHC in the absence of political demand by the citizen. J Family Med Prim Care, 5, 515-7.

Panagopoulou E, Papakosta D, Petridis D, et al (2015). Estimating the direct and indirect costs of lung cancer: a prospective analysis in a Greek University Pulmonary Department. J Thorac Dis, 7, S12-19

Reddy S, Selvaraj S, Rao K (2011). A Critical Assessment of the Existing Health Insurance Models in India. Public Health Foundation of India; 2011.

Stewart BW, Wild CP (2014).World Cancer Report 2014, World Health Organisation. Geneva; 2014.

Three-Year Report of Population Based Cancer Registries 20122014”. Bengaluru: National Center for Disease Informatics \& Research; 2016.

World Health Organisation. Cancer [Internet]. Available from: https://www.who.int/news-room/fact-sheets/detail/cancer).

World Health Organisation. Out-of-pocket payments, user fees and catastrophic expenditure[Internet].Availablefrom:http:// www.who.int/health_financing/topics/financial-protection/ out-of-pocket-payments/en/.

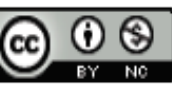

This work is licensed under a Creative Commons AttributionNon Commercial 4.0 International License. 